\title{
NIETzSCHE E Pascoaes, OU O SILENCIO COMO ACONTECIMENTO
}

\section{NIETZSCHE AND PASCOAES, oR SILENCE AS AN EVENT}

http://dx.doi.org/10.11606/issn.2175-3180.v13i25p184-201

Rodrigo Michell Araujo I

\section{RESUMO}

Este artigo visa analisar a presença de Nietzsche na obra poética de Teixeira de Pascoaes. Em vários momentos de sua criação literária, o poeta do Marão estreitou laços com o filósofo alemão, seja na poesia, como em Jesus e Pãa, ou na prosa, como na biografia de Santo Agostinho. No entanto, concentrar-nos-emos no diálogo entre os "personagens" Zaratustra (Nietzsche) e o Tolo (Pascoaes), a partir do qual argumentaremos que o silêncio se manifesta na obra de ambos como um acontecimento. Um silêncio que exige, sobretudo, uma "aprendizagem", revelando desde já o Nietzsche "educador" que Pascoaes leu. Espera-se com esse estudo demonstrar a importância de Nietzsche para a poesia de Pascoaes, viabilizando um caminho para entendermos o autor de $O$ Pobre Tolo como um poeta do silêncio, mas sobretudo como um dos nomes responsáveis pela circulação do pensamento nietzschiano na poesia e na cultura portuguesas.

\section{PALAVRAS-CHAVE}

Nietzsche; Pascoaes; Silêncio; Poesia; Filosofia.

\section{ABSTRACT}

This article aims to analyze the presence of Nietzsche in the poetic work of Teixeira de Pascoaes. At various points in his literary creation, the poet of Marão strengthened ties with the German philosopher, whether in poetry, as in Jesus e Pã, or in prose, as in Saint Augustine's biography. However, we will focus on the dialogue between the "characters" Zarathustra (Nietzsche) and the Tolo (Pascoaes), from which we will argue that silence manifests itself in their work as an event. A silence that requires, above all, a "learning", revealing now the Nietzsche "educator" that Pascoaes read. This study is expected to demonstrate the importance of Nietzsche for the poetry of Pascoaes, enabling a way to understand the author of $O$ Pobre Tolo as a poet of silence, but above all as one of the names responsible for the circulation of Nietzschean thought in poetry and in Portuguese culture.

\section{KEYWORDS}

Nietzsche; Pascoaes; Silence; Poetry; Philosophy.

\footnotetext{
${ }^{\text {I } U n i v e r s i d a d e ~ d o ~ P o r t o, ~ P o r t o, ~ P o r t u g a l . ~}$
} 
A poesia é sempre voz em luta íntima com o silêncio de onde nasce e para onde reflui uma vez nascida.

Eduardo Lourenço

\section{INTRODUÇ̣̂̃O}

Friedrich Nietzsche foi um filósofo diverso, e seu estilo "literário" é algo incontornável, tornando-o um autor bastante lido dentro e fora do âmbito da Filosofia. Também Teixeira de Pascoaes deixou uma obra múltipla, em suas cinco décadas de criação literária, alternando entre o verso e a prosa, mas também experimentando a biografia, o ensaio, o desenho, sendo objeto de interesse, em Portugal e não só, tanto da Literatura quanto da Filosofia. Nesse caso, a crítica (de ambos) sempre opta por uma "visão de conjunto", 1 não apenas para acompanhar a evolução dos temas, mas sobretudo para melhor definir o "pensamento" do autor. No entanto, privilegiaremos menos um exame integral das obras de nossos autores, e mais uma análise de temas e situações, dando ênfase àquilo que aproxima o filósofo e o poeta, nomeadamente a questão do silêncio, mas sem deixar de lado o exame "penetrante" 2 que ambas as obras exigem.

Em Nietzsche, interessa-nos sobretudo seu livro Assim falava Zaratustra, considerado pelo autor o seu "testamento", de acordo com uma carta a seu amigo Franz Overbeck, datada de 11 de fevereiro de 1883: "Agora eu acredito que ele constitua meu testamento" (NIETZSCHE; RÉE; SALOMÉ, 1979, p. 254). ${ }^{3}$ Trata-se de uma obra que funciona como um laboratório, na qual Nietzsche experimenta os temas capitais de seu pensamento, e que irão figurar de maneira mais ou menos expressiva em obras posteriores, bem como nos seus fragmentos póstumos e nas várias correspondências. ${ }^{4}$

\footnotetext{
${ }^{1}$ Veja-se, por exemplo, o que nos diz Karl Jaspers sobre Nietzsche, na minuciosa Introdução à filosofia de Friedrich Nietzsche, em que ressalta a importância do exame de sua obra "como um todo, levando a sério cada palavra, sem, contudo, se ater a uma palavra, isolando-a e restringindo nela a visão" (JASPERS, 2015, p. 3).

2 Apropriamo-nos de uma colocação de Jaspers sobre a maneira como se deve ler a obra de Nietzsche: "[Ela] precisa ser penetrante; ela não pode saber definitivamente, mas precisa proceder, sabendo aquilo que é respectivamente considerado, de maneira a questionar e responder" (JASPERS, 2015, p. 5).

3 Tradução nossa. No original: “Je crois maintenant qu'il constitue mon testament".

${ }^{4}$ Quanto ao "gênero" de Assim falava Zaratustra, temos uma obra de difícil classificação. Para André Schaeffner, em uma sucinta introdução à compilação da correspondência entre Nietzsche e seu interlocutor Peter Gast, esta obra alterna entre o poema, o romance, o ensaio autobiográfico, obra filosófica ou até composição musical. Ver Nietzsche, 1957a, p. 188. O próprio Nietzsche a classifica como uma sinfonia, como vemos em uma carta a Gast, de 2 de abril de 1883: “Em que categoria devemos colocar este Zaratustra? Estou quase certo de que esteja entre as sinfonias. É certo que, com ele, entrei em outro mundo" (NIETZSCHE, 1957b, p. 135). Também viu a obra como um poema, como diz em carta a Overbeck, de 1883: "é um poema e não uma coleção de aforismos" (NIETZSCHE; RÉE; SALOMÉ, 1979, p. 254). Com esses excertos, podemos
} 
Zaratustra ${ }^{5}$ é uma obra que inaugura na produção nietzschiana um novo ciclo $^{6}$ o que, para Charles Andler, representa a fase de "maturidade" do autor. ${ }^{7} \mathrm{O}$ seu sucesso é perceptível: o protagonista, uma espécie de profeta $^{8}$ que viveu dez anos encerrado em sua caverna, no alto de uma montanha e junto dos animais, tem de descer até a cidade ao encontro do povo, para lhes trazer uma "novidade", porém de maneira súbita e intempestiva. Durante os quatro livros, acompanhamos as idas e vindas de um errante dançarino, visto como "louco", a tentar comunicar-se com os homens, na busca incansável por "discípulos". No Prólogo, compreendido por dez parágrafos, acompanhamos a saída de Zaratustra da sua solidão e do seu silêncio montanhês. Ele busca os homens para lhes comunicar, diante da praça pública, o "além-do-homem", que dará "sentido à terra" (§ 3) e que permitirá a superação do próprio homem, mas, como tais colocações não são compreendidas, é chamado de louco, ${ }^{9}$ ou "um meio termo entre um louco e um cadáver" (NIETZSCHE, 2015, p. 37). Para Eugen Fink, um dos principais intérpretes do filósofo alemão, esta obra traz "parábolas impregnadas de um pathos poderoso" (FINK, 1976, p. 80),10 uma vez que a "mensagem" do personagem Zaratustra se encontra cifrada. Os seus interlocutores ainda não têm ouvidos preparados para o recebimento do conteúdo da mensagem, por isso Nietzsche, no desfecho do Prólogo, sinaliza a falta de preparação dos homens: “e a quem quer que

\footnotetext{
seguramente entender a obra como a mais híbrida do autor. Durante nosso estudo, teremos, portanto, a oportunidade de transitar (en passant), a partir das quatro partes que compõem Assim falava Zaratustra, pelos principais temas que, de algum modo, estruturam o pensamento nietzschiano: (i) a filosofia dos valores, (ii) a questão da moral, (iii) o entendimento do homem e do homem superior, (iv) a superação do próprio homem pela noção de além-do-humano, (v) a "morte de Deus", (vi) a doutrina do eterno retorno, (vii) a questão da verdade, (viii) o apolíneo e o dionisíaco, (ix) um pensamento bailarino, (x) o exame da existência, (xi) a vontade de poder e (xii) o niilismo.

${ }^{5}$ A partir daqui, assim nos referenciaremos à obra Assim falava Zaratustra.

${ }^{6}$ Em uma carta a Peter Gast (carta 119), datada de 1 de fevereiro de 1883, Nietzsche anuncia o título do seu novo livro e assim diz: "Com esse livro, eu entro em um novo ciclo" (NIETZSCHE, 1957b, p. 122).

${ }^{7}$ Cf. Charles Andler, La maturité de Nietzsche, 1928, p. 307.

${ }^{8}$ Nietzsche foi buscar à Pérsia uma referência para compor seu Zaratustra: Zoroastro. No fragmento póstumo número 148, datado de 1884, Nietzsche escreveu o seguinte sobre os persas: “Os Persas foram os primeiros a terem pensado a história em sua totalidade" (NIETZSCHE, 1982, p. 65). Mas, como chama a atenção André Schaeffner, "nenhum parentesco é perceptível entre os escritos atribuídos ao profeta e a obra de Nietzsche" (apud NIETZSCHE, 1957a, p. 200). Roberto Machado, em Zaratustra: tragédia nietzschiana, também observa que "a Grécia está bem mais presente no livro do que a Pérsia” (MACHADO, 2011, p. 36). ${ }^{9}$ No cinema, esta imagem está muito representada na cena final do filme Nostalgia (1983), de Tarkovsky: um profético personagem, Domênico, que sobe para uma estátua no meio de uma praça pública, anunciando ao povo a corrupção da sociedade, pedindo para que haja sol em plena noite. Certamente, temos aqui a poética leitura da superação do homem feita pelo cineasta russo, pondo nas palavras de Domênico a necessidade de que a noite se banhe com a luz apolínea.

10 Tradução nossa. No original: “Son parábolas impregnadas de un pathos poderoso”.
} 
tenha ainda ouvidos para as coisas inauditas, confranger-lhe-ei o coração com a minha ventura" (NIETZSCHE, 2015, p. 41-42) - não podemos, com esses excertos, deixar de apontar as reminiscências óbvias dos Evangelhos, de quando Jesus, depois de contar a parábola do semeador, esclarece aos discípulos por que fala à multidão por parábolas.

Tentemos, agora, esboçar algumas semelhanças entre o protagonista Zaratustra, de Nietzsche, e o personagem Tolo, de Pascoaes. Originalmente publicada em prosa, em 1924, O Pobre Tolo ganhou uma revisão ampliada, também em prosa, datada de 1930. Em 1929, Pascoaes "reescreve" a obra, dando-lhe uma versão em verso (volume VI das Obras Completas, editado pelo próprio autor). Nesta obra singular, acompanhamos os devaneios de um personagem magro e descalço sobre a ponte de São Gonçalo, em Amarante (que, por vezes, se confunde com a própria ponte), personagem caracterizado como "tolo e meio poeta" (PASCOAES, 1924, p. 35). Da ponte, as pessoas desacreditam o Tolo e suas palavras, julgando a sua "falta de razão": "riem-se dêle, às vezes; mas obedecem aos seus discursos incoerentes e nublosos que os atordôam e fazem scismar, devanear, num alheamento sonambólico e vago que é um dos primeiros sintomas da loucura" (PASCOAES, 1924, p. 62).

Quando Zaratustra é descrito como um "meio termo", entre o louco e o cadáver, a caricatura pascoaesiana está posta. Não seria, para os tolos e loucos, a sua loucura a sua própria liberdade? Afinal, "os doidos libertamse na sua loucura" (PASCOAES, 1924, p. 62). O Tolo crê na sua loucura como sabedoria. Quando se fala em "loucura", para ele, se está a falar em "razão", pois, como afirma o próprio Tolo, "a loucura santifica a razão" (PASCOAES, 1924, p. 74). Assim, podemos afirmar que o Zaratustra é uma espécie de Tolo, e que o Tolo corporiza a antológica afirmação de Gilbert Chesterton, em Ortodoxia: "o louco é um homem que perdeu tudo exceto a razão" (CHESTERTON, 2008, p. 19).

Outra afinidade entre ambos os personagens está na crítica àquilo que Nietzsche classificou, via Zaratustra, como populaça, ou os "bons burrinhos e burrinhas de carga" (NIETZSCHE, 2015, p. 66). No capítulo "Dos pregadores da morte", temos o mais claro diagnóstico de Nietzsche para a necessidade de "transvalorizar todos os valores" - um dos pilares de seu pensamento. Os homens tornaram-se obedientes, supérfluos, superficiais. São "tísicos da alma" (NIETZSCHE, 2015, p. 72) que se acomodaram - corporalizando, de algum modo, a ideia schopenhauriana 
de que a vida é puro sofrimento. Daí ser possível a Nietzsche avaliar o niilismo europeu em seus diversos níveis. ${ }^{11}$

$\mathrm{Na}$ interpretação de Jaspers sobre o projeto nietzschiano de "transvaloração de todos os valores", aquilo que o homem dispõe para lutar contra os homens de rebanho é a possibilidade de criar. $\mathrm{O}$ "homem é o ser que avalia, que mede, que valora e, aí, é criador, não há valores absolutos, que subsistam como um ser e que precisam ser apenas descobertos [...]" (JASPERS, 2015, p. 211-212, grifo no original). De maneira análoga a Zaratustra, o Tolo é visto pelos demais como um "estranho". E é na sua "loucura" que fará uma "avaliação" do meio exterior, distinguindo-se ele mesmo dos demais homens, chamados de "homens de juízo". O Tolo falará desses homens com um desdém que é herdeiro do que Nietzsche anunciou em Ecce homo: o "nojo do homem, eis o meu perigo" (NIETZSCHE, 1997a, p. 137, grifo no original). Para o Tolo, os "homens de juízo" apenas tateiam a realidade:

És um tolo superior aos homens de juízo que possuem a realidade por intermédio do tacto, como qualquer animal incipiente. E imaginam conhecê-la, porque desconhecem os sonhos. Não se entendem naquelas brumas misteriosas e longínquas, onde os tolos assistem ao desabrochar duma estrêla. E ficam radiantes, com um sorriso na alma, para sempre (PASCOAES, 1924, p. 82, grifo nosso).

Assim, é na imagem do "desajuste" com a realidade que Teixeira de Pascoaes extrai as lições nietzschianas para estruturar O Pobre Tolo, sobretudo por dois motivos. Primeiro, pela ação criadora que encontramos na obra (tanto nas versões em prosa ou verso), pois o Tolo a todo o momento devaneia e parece se situar no domínio dos sonhos, mas de um sonho que é a sua realidade, pois, de maneira, por assim dizer, muito clariceana, é na intersecção entre sonho e realidade que o personagem se insere - e que nos conduz a um dos pilares fundamentais da obra poéticofilosófica de Pascoaes, que é a fantasmagoria. ${ }^{12}$ Segundo, pela atividade

\footnotetext{
11 Torna-se Nietzsche um grande crítico da moral através desta crítica, que atingirá não apenas a moral cristã, mas também a sociedade, a modernidade, a cultura. Apesar de já ter preambulado o tema em Humano, demasiado humano - quanto à questão da moral em Humano, demasiado humano, podem-se conferir os fragmentos reunidos no segundo capítulo, "Para a história dos sentimentos morais" - é na obra A genealogia da moral que o filósofo falará do homem doente de si mesmo, que é "consequência de um divórcio violento com o passado animal, de um salto para novas situações, para novas condições de existência, de uma declaração de guerra contra os antigos instintos que antes constituíam a sua força e o seu temível caráter" (NIETZSCHE, 1997b, p. 70).

${ }^{12}$ Em outro momento, já tratamos de uma leitura fenomenológica do sonho em Teixeira de Pascoaes e de suas implicações na sua obra, sobretudo em O Doido e a Morte, de 1913. Interpretação realizada a partir da
} 
avaliadora empreendida pelo Tolo, de maneira muito análoga à de Zaratustra, a fazer um "diagnóstico" de tudo que está ao seu redor mesmo que sem as pretensões nietzschianas de esboroamento, afinal, "o tolo não se liberta de si mesmo, e põe-se a estudar e a analisar o cárcere onde vive prisioneiro" (PASCOAES, 1924, p. 86). Essas são, para nós, as condições necessárias não só para o delineamento das afinidades entre ambos, mas também para a manifestação do silêncio.

\section{UM PENSAR AFIRMATIVO}

Para uma interpretação do silêncio como acontecimento em Nietzsche e em Pascoaes, é incontornável a contestação do pensamento platônico que ambos os autores esboçam, cada um de seu modo, nomeadamente sobre a negação do mundo sensível em prol de outro mundo ${ }^{13}$. Em "Da vitória sobre si próprio", Zaratustra quer alertar para o perigo de criar outros mundos: "quereis primeiro criar um mundo tal que possais adorá-lo de joelhos; é a vossa última esperança [...]" (NIETZSCHE, 2015, p. 159). Temos aqui uma das principais críticas de Nietzsche a uma série de dualismos presentes na filosofia platônica, como, por exemplo, entre mundo inteligível e o mundo sensível. Mas o combate nietzschiano acaba por centrar-se no modo como o cristianismo teria distorcido o platonismo no intuito de depositar esperanças em outro mundo, julgado melhor que este ${ }^{14}$. Sem a pretensão de nos alongarmos, parece-nos sugestiva, no capítulo "O que devo aos Antigos" de O crepúsculo dos ídolos, a maneira como Nietzsche faz longas críticas a Platão, visto como "aborrecido", figurando no rol da décadence: "Platão é um covarde perante a realidade - por conseguinte, foge para o ideal" (NIETZSCHE, 2018, p. 107,

\footnotetext{
fenomenologia de Leon Daudet e de seu conceito de rêve éveillé (sonho acordado), datado de 1926, fundamental para os estudos posteriores no campo do imaginário. Ver Araujo, 2020a.

${ }^{13}$ Assumimos o risco de tal afirmação, apesar de, em determinados pontos, Teixeira de Pascoaes manter-se em sintonia com algum pensamento platônico, especialmente quando o poeta busca no pensamento da Antiguidade a noção de "harmonia" para compor uma espécie de "sentido musical" para sua obra.

${ }^{14}$ Curioso é o comentário de Nietzsche, no § 374 de A gaia ciência: "Só podemos ver com nossos olhos; é uma curiosidade sem esperança de êxito de procurar que outras espécies de intelectos e de perspectivas podem existir" (NIETZSCHE, 2000, p. 274). Com este excerto podemos pensar numa das principais críticas de Nietzsche, a oposição à teoria dos dois mundos, ou seja, a negação dos ideais platônicos. Nietzsche empenhar-se-á fortemente na argumentação de que a divisão dos mundos entre mundo verdadeiro (inteligível) e mundo aparente (sensível) é falsa e supérflua. O filósofo de Ecce homo acaba por opor-se à tentativa platônica de demonstrar que este nosso mundo é "aparente", enquanto uma outra realidade é tida como "verdadeira", superior, logo, melhor. Para uma melhor compreensão, veja-se, por exemplo, o §6 ("A 'razão' na Filosofia) de O crepúsculo dos ídolos, onde Nietzsche interpreta o platonismo como uma "depreciação da vida". Ver Nietzsche, 2018, p. 31.
} 
no original), pois, ao se desviar de um pensamento helênico criador e afirmativo perante a vida e ao voltar os olhos para outro mundo, inteligível, inevitavelmente o platonismo desqualifica este mundo. Logo, uma desqualificação em prol de pré-juízos filosóficos, religiosos e morais.

$\mathrm{O}$ que nos interessa em Nietzsche e na sua ideia de décadence (Sócrates) é a sua noção de "desqualificação" do mundo sensível que o projeto platônico apresenta como "desvalorização" deste mundo que é o nosso, entendido por Nietzsche como um "envenenamento". ${ }^{15}$

Quando perguntamos qual o sentido de "mundo" em Teixeira de Pascoaes, precisamos pôr em destaque a expressão "Outro Mundo", corrente em sua obra. Mas sejamos cautelosos com o entendimento desta expressão, pois, pode sugerir a compreensão de que o poeta está a arquitetar uma outra realidade, ou melhor, mundos possíveis. Decerto o sujeito lírico pascoaesiano constantemente devaneia um outro mundo. No entanto, o devaneio com uma outra realidade nunca significa fuga, muito menos negação desta, mas justamente o oposto: o poeta visa a um encontro com a realidade para, assim, poder afirmá-la. Em O Pobre Tolo, vemos que a personagem herda a força nietzschiana para o combate, ao tentar alcançar a realidade que lhe é fugidia: "luta para atingir a sua própria realidade que lhe foge, como diluída em nevoeiro" (PASCOAES, 1924, p. 58). Se o Tolo tem o sentimento de que a realidade the escapa às mãos, é porque ela lhe aparece em forma de esboço. Em um sonho aéreo, o Tolo vê a vida do alto, "e o mundo aparece, cá em baixo, num esbôço transfigurado e grandioso" (PASCOAES, 1924, p. 59).

Podemos, então, afirmar que a obra $O$ Pobre Tolo corporaliza aquilo que Jaspers definiu como linha de força na obra nietzschiana, isto é, um pensar afirmativo da vida e "em nome da vida" (JASPERS, 2015, p. 455), que não sucumbe à contraposição de mundos, muito menos teme a morte.

\section{ACONTECER DO SILÊNCIO}

Acreditamos que foi possível a Nietzsche e a Pascoaes um pensar afirmativo da existência porque ambos dialogaram intensamente com o silêncio. O poeta e o filósofo encontraram no silêncio um interlocutor. Em Zaratustra, diversas são as passagens em que o tema do silêncio se manifesta, figurando em todos os quatros livros. Zaratustra irá valorizar o silêncio e a

\footnotetext{
${ }^{15}$ Ainda em O crepúsculo dos ídolos, ver o §35, “Incursões de um Extemporâneo": “uma tal vegetação venenosa, brotando da putrefação, envenena com a sua exaltação a vida" (NIETZSCHE, 2018, p. 86, grifo no original).
} 
solidão da sua montanha, visto que o profético personagem ainda está a aprender como comunicar-se com os homens e como lhes transmitir a sua mensagem do além-do-homem. Em “Da castidade", Zaratustra diz: “Gosto da floresta. Vive-se mal nas cidades" (NIETZSCHE, 2015, p. 83). A floresta possibilita a recolha, o repouso, a comunicação com os animais, nomeadamente a águia e a serpente - metáforas importantes para o pensamento do eterno retorno no terceiro livro. Ainda no terceiro livro, quando conversa com a Vida, esta alerta-o para os perigos do ruído: "bem sabes que o barulho mata os pensamentos" (NIETZSCHE, 2015, p. 309).

A morada de Zaratustra é decerto no silêncio, "no alto dos montes silenciosos" (NIETZSCHE, 2015, p. 120). É ao silêncio montanhês que a personagem regressa depois do frustrante encontro com os homens da cidade. Esse regresso terá implicações positivas e cruciais para Zaratustra, pois é no silencioso recolhimento que ele desenvolverá e reformulará o seu pensamento de criação. Nas "Ilhas afortunadas", passa a esculpir a vontade criadora, enquanto sente o que há de silencioso e leve ao seu redor: "acabarei a minha estátua, porque me apareceu uma Sombra, veio até mim o que há de mais silencioso e mais leve no mundo" (NIETZSCHE, 2015, p. 125-126). Logo, podemos observar que é no primeiro livro que o silêncio assume uma dimensão mais espacial.

É no segundo livro de Zaratustra que acompanhamos de perto uma audibilidade do silêncio, quando observamos Zaratustra a conversar com o silêncio, na hora do supremo silêncio. Uma conversa em sonho: "avançaram os ponteiros, o relógio da minha vida pareceu suspender o movimento... nunca ouvi tal silêncio à minha volta, e o meu coração foi apertado pelo assombro" (NIETZSCHE, 2015, p. 202). É o silêncio personificado que encoraja Zaratustra e o impele a um pensamento tempestivo. A "hora do supremo silêncio" lhe diz: "são as palavras mais silenciosas que trazem a tempestade" (NIETZSCHE, 2015, p. 204).

De maneira análoga, entendemos ser esta "hora do supremo silêncio" a "Musa" que sussurra no ouvido do Tolo (também no de Pascoaes?) para lhe aconselhar tempestivas palavras silenciosas. O Tolo, que nasceu de uma queda das nuvens ${ }^{16}$, está em constante conversa com o silêncio, sendo ele próprio fruto do silêncio, pois "o tolo é silêncio e luar" (PASCOAES, 1924, p. 36). Logo no início do segundo capítulo, o silêncio se

\footnotetext{
${ }^{16}$ Logo no primeiro capítulo, acompanhamos a descrição deste personagem, que "caiu das nuvens e não pode regressar às nuvens" (PASCOAES, 1924, p. 16).
} 
configura como o lugar de repouso do Tolo, o seu "leito", fora do palco do mundo, mas ainda teatro do mundo:

Passou a tempestade vicentina. Silêncio; não o silêncio da lua de que nos fala Virgílio, nem o das almas meditativas, irmãs do pobre tolo: é o silêncio em que se converte o sermão das nuvens, - um precipício onde tombamos com delícia, porque os medonhos sons atroadores levam-nos pelas orelhas, não sei a que negras altitudes!

$\mathrm{O}$ silêncio é um leito de plumagens e veludos. Nêle repousaria o tolo, sossegado; adormeceria, se a toleima e o sono fôssem, por bom acaso, compatíveis (PASCOAES, 1924, p. 46).

Neste momento, o Tolo ainda vê o silêncio como a oposição do barulho, pois o ruído impede o pensamento. É preciso tomar o silêncio enquanto recolhimento, por isso, mais adiante, dirá o Tolo que “a alegria é dispersiva; é curiosa como as crianças; mas a tristeza, que é alegria envelhecida, concentranos em nosso pensamento" (PASCOAES, 1924, p. 47). Ou seja, se o barulho se configura como um obstáculo ao pensamento, para o Tolo o pensamento depende deste repouso no silêncio. A presença do "pensamento de abismo" nietzschiano, aqui, é clara: é o repouso no silêncio que permite ao Tolo voltar os olhos para a realidade, tentar conhecê-la, fazê-la superar o caráter de mero esboço, em síntese, alcançar a realidade que lhe é fugidia:

O silêncio é um mar onde o pobre tolo mergulhou, seduzido pelo mistério das profundidades tenebrosas [...]

Aqui e além, cristalizam e refulgem as arestas da Realidade; gritos de luz que rasgam os seios da sombra ilimitada... Gritos de luz, cristais num delírio de scintilações multicolores, aflorando no mar infinito do Silêncio (PASCOAES, 1924, p. 75-76).

Invariavelmente, esse repouso do Tolo nos coloca diante do paradoxo inerente ao silêncio. Enquanto este aparentemente parece dispensar a linguagem (a palavra, o logos etc.) - o que, para alguns, seria o silêncio algo equivalente ao vazio, coisa oca, um "nada" -, é a ela a quem sempre recorremos para tornar o silêncio mais visível, ali mesmo no horizonte do mundo linguístico onde a linguagem incorpora o silêncio fazendo-se "linguagem muda" (MERLEAU-PONTY, 2015, p. 79), pois o silêncio percebido e experienciado, se assim pensarmos junto com Merleau-Ponty, também é linguagem, comunica. Nunca é um vazio, senão um vazio cheio. $\mathrm{O}$ silêncio abre a linguagem para aquilo que ela tem de possibilidade e 
impossibilidade, de exprimível e de inexprimível, de explicável e de inexplicável. Em Pascoaes, o repouso acaba sendo um "caminho" que viabiliza a linguagem do silêncio, esta linguagem tão bem pressentida pelo poeta e radicalmente presente em suas obras. Mas repouso, em Pascoaes, jamais quer dizer inércia. Ao contrário, é ação, é caminho para um "encontro". Basta situarmos que Pascoaes, em seu solar em Gatão, tinha um gosto especial pelo seu repouso, em seu quarto-escritório, com mobílias curiosamente e estranhamente planejadas pelo próprio poeta em forma de triângulo, além de uma grande janela que era sua "porta" para a Natureza, é neste espaço que o poeta compunha e cultivava o silêncio. Mas não era Pascoaes um homem isolado, como se pode pensar, pois foi no repouso de seu quarto-mundo que o poeta procurava encontrar a (sua) realidade. Isso acaba se refletindo em sua obra, seja em verso ou prosa, onde avulta uma espécie de "escuta" do silêncio que não quer dizer apenas ouvir passivamente com os órgãos responsáveis pela audição, mas um ouvir com o corpo e com a imaginação. Vejamos o que diz o poeta na obra memorialística Uma fábula (o advogado e o poeta), escrita em 1952 (ano de sua morte) e publicada em 1978, também entendida pelo autor como uma continuação do Livro de memórias, datado de 1928: "Sou mais sujeito às alucinações auditivas que às visuais, como se a minha fantasia estivesse mais perto dos meus ouvidos que dos meus olhos" (PASCOAES, 1978, p. 57).

Acreditamos que é na escuta atenta do silêncio, nesta "alucinação auditiva", que Pascoaes apreende o mundo como coisa indefinida, vaga e incerta, três vocábulos tão presentes em inúmeros versos. E, como exímio leitor que foi, advém daí seu interesse pelo "princípio da incerteza" de Heisenberg e pela física quântica ${ }^{17}$. Se a realidade se apresenta para Pascoaes como incerteza física, que pode despoletar uma incerteza metafísica, nada mais justificável, segundo António Cândido Franco (2014, p. 266), que "criar um pensamento solitariamente [...] indeterminado". Acompanhamos, aqui, o ensaísta para entender o silêncio como uma via em que o poeta pode tatear os fragmentos incertos da realidade, ou daquilo que entende por realidade - por isso vale destacar que, em sua obra, o silêncio acaba sendo um problema complexo, assumindo diversos contornos e manifestações (espaço-temporais) ${ }^{18}$.

\footnotetext{
${ }^{17}$ No ensaio "Teixeira de Pascoaes e o indeterminismo da saudade" (2002), António Cândido Franco destaca a presença de Heisenberg na órbita dos interesses de Pascoaes. Ver Franco, 2014, p. 265.

${ }^{18}$ Em outro momento, estudamos amplamente as manifestações do silêncio e suas implicações na obra de Teixeira de Pascoaes. Ver Araujo, 2020b.
} 
Se, no pensamento de Nietzsche, o que define a realidade é tão somente a interpretação que dela fazemos (cf. JASPERS, 2015, p. 435), a interpretação da realidade feita pelo Tolo é apenas possível através de sua atividade criadora. Daí o silêncio garantir ao Tolo a possibilidade de criar. E, por isso, defendemos sempre a tese de que, em Pascoaes, temas como o sonho e o devaneio (com "Outro Mundo") não tipificam uma fuga à realidade, mas o seu oposto.

Quando Nietzsche fala do mundo como fenômeno da vontade de poder, Jaspers interpreta que "a vontade de poder não produz nenhum mundo cristalizado de formas, um mundo dotado de uma duração eterna, mas transforma esse mundo em um devir constante" (JASPERS, 2015, p. 440). Jaspers aqui toca sutilmente num conceito nietzschiano que, a nosso ver, está também presente em Pascoaes: o devir.

Todo o pensamento trágico do pathos de Nietzsche nos ajuda a entender a noção de devir como processo, como um vir-a-ser constante entre um construir e um destruir. Ora, em Pascoaes este devir está presente em $O$ Pobre Tolo, quando o personagem se compara a um pedreiro, buscando criar-se a si mesmo e à própria realidade. O Tolo vê-se a si próprio como um esboço, como algo ainda em construção:

Todavia, o pobre triste lida com pedras e calhaus. Pica que pica, sua que sua, cinzela que cinzela! O seu desejo é arrancar àquelas brutas massas informes, um aspecto em que reveja o seu perfil, uma expressão em que vislumbre a sua alma. A sua ideia é criar a sua pessoa. E trabalha e trabalha a matéria prima que ele trouxe do ventre materno (PASCOAES, 1924, p. 100).

É enquanto "sujeito criador e artista" (NIETZSCHE, 1997c, p. 225, grifo no original) que o Tolo empreende uma "filosofia do devir". Nas duas versões de O Pobre Tolo (prosa e verso), podemos verificar que o devir, para Pascoaes, constitui o caráter mutável e cambiante da existência. Na primeira edição, de 1924, o devir necessita do espírito de criança, para lembrar da metamorfose do espírito anunciada por Zaratustra:

Nós, os pedreiros, trabalhamos a cantar. As pedras submetem-se ao nosso esforço harmonioso e mostram a forma ideal que lhe imposemos, - o mesmo perfil do nosso sonho. Nós, os pedreiros, transmigramos para as pedras; conhecemo-las por dentro. Por dentro, todas as cousas são iguais. Encontramo-nos na intimidade duma pedra; encontramos, ali, a nossa infância original (PASCOAES, 1924, p. 60, grifo nosso). 
Para o Tolo-pedreiro, o devir tem de ser um devir-criança. Este devir é fundamental para o personagem criar a realidade, ou em termos nietzschianos, para interpretá-la distanciando-se, como artista que é sensível à construção e destruição. $\mathrm{O}$ Tolo tudo observa com distanciamento, por isso vê tanto a vida quanto si próprio como "esboço"19. "E logo o mundo / cá em baixo, aparece num esboço / transfigurado" (PASCOAES, 1970, p. 250). Ao ter a perspectiva do esboço, poderá o Tolopedreiro "trabalhar a existência", como vemos na seguinte estrofe da versão em verso:

\section{[...] É pedreiro}

E músico. Trabalha, mas cantando.

Assim trabalha as pedras da Existência.

Nelas esculpe estátuas de demónios;

E nas nuvens modela bustos de anjos...

As nuvens e os fraguedos obedecem

Ao seu esforço harmonioso, e tomam

Atitudes humanas e divinas.

Conhece a Realidade - bruta fraga -

E o sonho - etérea nuvem indecisa...

Porque ele existe e vive [...] (PASCOAES, 1970, p. 251).

Outro ponto importante de $O$ Pobre Tolo é quando Pascoaes recorre à imagem do pintor. O "sol" e o "inverno" aparecem no texto como pintores, poetas mudos, para lembrar Simónides de Ceos. Sobre a ponte, o Tolo vê que

o sol veste os fantasmas de carne viva e molha-os, por dentro, em sangue vivo, - o mesmo sangue das suas veias.

É um pintor de painéis o sol; um trágico pintor. A sua tinta é sangue vivo; espalha-a na tela que se encandeia e contorce e grita (PASCOAES, 1924 , p. 183 , grifo nosso). ${ }^{20}$

\footnotetext{
19 Não deixemos de lado, mesmo que em nota, a presença sempre importante de Raul Brandão, especialmente nestas "imbricações" entre o físico e o metafísico presente na obra de ambos. Um "grande amigo" de Pascoaes (vale destacar que ambos dividiram a autoria da peça Jesus Cristo em Lisboa, estreada na capital portuguesa em 1927), autor com quem partilhou muitos de seus pensamentos, inclusive a compreensão de esboço existencial que aqui tratamos.

${ }^{20}$ Aqui, é estreita a relação que o Tolo estabelece com os desenhos do próprio Teixeira de Pascoaes, pois os seus desenhos são gritos e a cor é de sangue e fogo. Ver Pascoaes, 2002, p. 156-159. E também Anjos e fantasmas (2003), que se faz complemento à obra Desenhos.
} 
Mais adiante, já passada a sua adorada primavera, o Tolo põe-se a contemplar o inverno, o que lhe permite afirmar ser esta a estação mais propícia à manifestação do silêncio: “O inverno adora o silêncio; não é músico; é um pintor, - o pintor elegíaco do roxo e do cinzento, as duas tintas da Tristeza" (PASCOAES, 1924, p. 190, grifo nosso). Deve-se notar que, nesta edição de 1924, não há nenhuma passagem em que o Tolo explicitamente se compare a um pintor, ele apenas projeta o silêncio de uma Natureza. No entanto, na edição em verso, podemos observar que o Tolo está envolto do elemento trágico e do elegíaco, o que nos permite elaborar a seguinte hipótese: é no verso que o Tolo absorve a pintura trágica e elegíaca da Natureza, convertendo-se ele mesmo em pintor trágico e elegíaco, para a partir daí dar cor e corpo à existência, uma vez que "o esboço e a pintura equivalem-se" (PASCOAES, 1924, p. 103). No fragmento $\mathrm{V}$ da edição em verso, temos a seguinte descrição do Tolo: "és um jumento / perdido neste mundo; mas a tua / sombra humana nos astros se projecta / és uma grave e trágica pessoa" (PASCOAES, 1970, p. 225). Já no fragmento XXVI, lemos o seguinte verso: "o tolo é uma elegia, em verso brando" (PASCOAES, 1970, p. 245).

Enquanto pintor, o Tolo pode ver a existência como uma tela, mas ainda com traços indefinidos e que precisam ser realçados. $\mathrm{O}$ pedreiro e $\mathrm{o}$ pintor são apenas metáforas usadas por Pascoaes para demonstrar a vontade criadora do Tolo. Se Zaratustra, no $\S 11$ do "Canto da embriaguez", no último livro, nos mostra a vontade criadora em forma de sede, alertando aos "homens superiores" para que tenham "sede de vós" (NIETZSCHE, 2015, p. 432), o Tolo, "em procura de si mesmo" (PASCOAES, 1924, p. 182), converte a sede em fome: "lobos, cães vadios e poetas: três irmãos no luar, famintos de sombra e de mistério. Três esqueletos do mesmo osso, espelhando o mesmo luar, a mesma fome" (PASCOAES, 1924, p. 120).

Parece-nos curioso a este propósito o $§ 182$ do terceiro livro de A Gaia Ciência, onde Nietzsche diz que "quando se vive só, não se fala muito alto, não se escreve também muito alto [...]. A solidão modifica as vozes" (NIETZSCHE, 2000, p. 159). Aqui, Nietzsche decerto preambula a voz do silêncio que terá destaque em Assim falava Zaratustra e de igual modo em $O$ Pobre Tolo.

Tanto Zaratustra quanto o Tolo são poetas do silêncio, pois ambos retiram do silêncio o seu saber, aprendem com o "bem-aventurado silêncio" 
que os cerca e, deste modo, é pela via do silêncio que ambos os personagens transmitem os seus pensamentos aos homens, como vemos no terceiro livro de Zaratustra: "E lembras-te, ó Zaratustra, da Hora do supremo silêncio, que te arrancou a ti próprio segredando-te com voz maliciosa: 'diz o que tens a dizer, e depois sucumbe!'” (NIETZSCHE, 2015, p. 252). Já para o Tolo, o silêncio é uma exigência de seu próprio Ser, uma necessidade vital.

Em Uma fábula, ${ }^{21}$ Teixeira de Pascoaes relembra que, na época em que se tornou bacharel em Direito, vivia em constante luta consigo mesmo, um duelo entre o sagrado e o profano, entre as leis e a poesia ${ }^{22}$. Mas foi a vitória da última que fez do próprio poeta um Tolo: "Venceu esta, naturalmente, que ninguém foge às leis da Natureza. Em vez dum advogado citadino, fiquei a ser um pobre tolo, olvidado, durante anos e anos, nas profundezas duma aldeia!" (PASCOAES, 1978, p. 170). O poeta precisa, primeiramente, ser um Tolo, só então poderá ser um poeta do silêncio. É, portanto, de Uma fábula que retiramos a ideia do poeta-tolo como poeta do silêncio: "E um poeta só é Poeta nos seus silêncios metrificados e rimados" (PASCOAES, 1978, p. 114). E todo poeta do silêncio só o é quando se encontra suspenso "entre extáticas margens de silêncio" (PASCOAES, 1970, p. 276) - este verso pascoaesiano poderia, sem dúvida, ser uma fala de Zaratustra.

Sobre Assim falava Zaratustra, Eugen Fink afirma que a obra "não tem o caráter de uma mera invenção. Atrás dela se encontra uma grande força e é a partir dela que devemos entendê-la" (FINK, 1976, p. 74). ${ }^{23}$ Apropriamo-nos desta citação de Fink, pois, para Nietzsche e Pascoaes, a "grande força" inominada é decerto a força do silêncio.

Com efeito, é de Nietzsche/Zaratustra que Pascoaes extrai o saber necessário para estruturar o seu "silêncio metrificado e rimado", como lemos em Uma fábula. Afinal, para ambos há um fundo musical no silêncio ${ }^{24}$. Inspirado em Nietzsche, o Tolo canta e dança porque a própria dança (força dionisíaca) tem poder de revelar o segredo da vida, pois “a dança

\footnotetext{
${ }^{21}$ Assim abreviaremos a obra Uma fábula (o advogado e o poeta).

${ }^{22}$ Fazemos referência à seguinte passagem do texto: “Digladiavam-se, em mim, o profano e o divino, o poeta, por graça de Deus, e o bacharel, por arte do diabo" (PASCOAES, 1978, p. 162).

${ }^{23}$ Tradução nossa. No original: “No tiene el carácter de una mera invención. Tras él se encuentra una gran fuerza y desde ella devemos entenderlo".

${ }^{24}$ Roberto Machado, ao indagar se seria Zaratustra uma obra musical, elabora a seguinte hipótese: "considerar o Zaratustra canto significa dizer que nele a palavra canta pela própria musicalidade da palavra" (MACHADO, 2011, p. 24). No horizonte do silêncio, podemos reelaborar esta hipótese de Roberto Machado. Se consideramos a obra como um canto, é porque Zaratustra percebeu o som do silêncio que está por detrás da palavra. A obra pode ser interpretada, portanto, como uma música do silêncio, na pausa musical.
} 
seduziu o tolo. Revelou-lhe o segrêdo da vida que é um ímpeto musical da Natureza, - o cântico da Terra" (PASCOAES, 1924, p. 116). E se advém de Zaratustra a fala de que "[...] os maiores acontecimentos surpreendem-nos não nas horas mais barulhentas, mas nas horas mais silenciosas" (NIETZSCHE, 2015, p. 184), temos, enfim, a maior lição que Pascoaes talvez tenha retido da obra de Nietzsche, que é, sem dúvida, o entendimento do silêncio como um grande acontecimento.

\section{CONCLUSÃO}

As relações entre Nietzsche e Pascoaes são extensas e não se esgotam por aqui, de maneira que o "concluir" é tão somente um fluxo de água corrente, ou, como afirmou o próprio poeta, na prosa filosófica $O$ Bailado, "o caminho é uma pegada mais extensa, branquejando através dos panoramas. É o leito dum rio onde correm as ondas vivas do Tempo" (PASCOAES, 1973, p. 131).

A relação de Pascoaes com Nietzsche não se resume apenas na ordem do "intertexto". Não podemos esquecer que Pascoaes foi também um grande leitor, sobretudo de língua francesa, e mesmo o Nietzsche que leu, por não ter domínio da língua alemã, foi por intermédio de traduções francesas. Uma das características mais marcantes de sua poesia, como também da prosa, é decerto o convite ao diálogo que suas inúmeras obras propõem (seja com outros autores ou com outras formas do pensamento). Sem dúvida, uma etiqueta bastante sincera e cabível para Pascoaes é a de "pensador", sobretudo pelas constantes inquietações e interrogações que perfilam sua obra. No caso de sua relação com Nietzsche, é inegável o contributo que Pascoaes deu à literatura e cultura portuguesas no que concerne à circulação do pensamento nietzschiano, somando-se, assim, a uma plêiade de autores, ${ }^{25}$ em Portugal, que se esforçaram em "pensar Nietzsche". ${ }^{26}$

Para o nosso propósito de averiguar as afinidades entre Zaratustra e o Tolo, tivemos que deixar de lado tantas outras obras de Pascoaes nas quais se avulta o pensamento nietzschiano, mesmo nas inúmeras reticências que Pascoaes insistiu como recurso em seus versos,

\footnotetext{
${ }^{25}$ A título de nota, vale conferir a tese de doutoramento de Américo Enes Monteiro, A recepção da obra de Friedrich Nietzsche na vida intelectual portuguesa (1892-1939), defendida na Universidade do Porto em 1997, na qual interpreta Teixeira de Pascoaes como um poeta difusor do pensamento nietzschiano. Ver Monteiro, 1997, p. 149.

${ }^{26}$ Não deixemos de destacar a prosa Duplo passeio (1942), em que Pascoaes faz remissões precisas a Nietzsche, obra que recebeu o suntuoso elogio de António Cândido Franco (2014, p. 261) de ser "talvez o livro mais importante da literatura portuguesa do século XX".
} 
configurando aquilo que em Retórica se chama "aposiópesis". Por exemplo, em Jesus e Pã, obra de 1903 e já fortemente influenciada por Nietzsche, pois todo o poema trata de uma conversa do sujeito lírico com um velho sábio e enigmático que vive na serra - não se teria, aqui, Pascoaes inspirado em Zaratustra? O sujeito lírico quer aprender com este velho personagem, pois "o que pra mim era silêncio, ele escutava... / e logo conheci que ele entendia tudo" (PASCOAES, 1996, p. 164).

Ainda que as reticências persistam, no tecido textual e no próprio pensamento, continuamo-las nós, leitores, como o Tolo, à sombra do Tâmega, mergulhado nas ondas da realidade e à escuta de um silêncio que o possibilite tonificar as tintas da sua existência, porque, à maneira de Nietzsche, entendeu o poeta uma fórmula que se encontra presente em suas mais de vinte obras publicadas, a de que o silêncio é sempre igual a criar. Se, por fim, em um dos momentos mais marcantes de $O$ Pobre Tolo, o quimérico personagem afirma que "a vida é imperfeição, esbôço, nuvem..." (PASCOAES, 1924, p. 164), é preciso que o silêncio sempre aconteça e se renove. Pois é ele que garante o duplo jogo de aprendizado e de ensino. É, então, o silêncio o "leito" que guarda o seu repouso - e também não é ele o leito que guarda a própria poesia?

\section{REFERÊNCIAS}

ANDLER, Charles. La maturité de Nietzsche jusqu'à sa mort. Paris: Éditions Bossard, 1928.

ARAUJO, Rodrigo Michell. "O problema da morte na poesia de Teixeira de Pascoaes". Antares: Revista de Letras e Humanidades, v. 12, n. 26, mai./ago., p. 49-68, 2020a.

ARAUJO, Rodrigo Michell. Silêncio e poesia em Teixeira de Pascoaes. 2020. 262f. Tese (Doutorado em Filosofia) - Faculdade de Letras da Universidade do Porto, Porto, Portugal, 2020b.

CHESTERTON, Gilbert. Ortodoxia. Trad. Almiro Pisetta. São Paulo: Mundo Cristão, 2008.

FINK, Eugen. La filosofía de Nietzsche. Trad. Andrés Sánchez Pascual. Madrid: Alianza Editorial, 1976.

FRANCO, António Cândido. Trinta anos de Dispersos sobre Teixeira de Pascoaes. Lisboa: Imprensa Nacional - Casa da Moeda, 2014. 
JASPERS, Karl. Introdução à filosofia de Friedrich Nietzsche. Trad. Marco Antônio Casanova. Rio de Janeiro: Forense Universitária, 2015.

MACHADO, Roberto. Zaratustra: tragédia nietzschiana. Rio de Janeiro: Jorge Zahar, 2011.

MERLEAU-PONTY, Maurice. Fenomenologia da percepção. Trad. Carlos Alberto Ribeiro de Moura. São Paulo: Martins Fontes, 2015.

MONTEIRO, Américo Enes. A recepção da obra de Friedrich Nietzsche na vida intelectual portuguesa (1892-1939). 1997. 552f. Tese (Doutorado em Cultura Alemã) - Faculdade de Letras da Universidade do Porto, Porto, Portugal, 1997.

NIETZSCHE, Friedrich. Lettres à Peter Gast. Intr. e notas André Schaeffner. Trad. Louise Servicen. Mônaco: Éditions du Rocher, 1957a.

NIETZSCHE, Friedrich. Lettres à Peter Gast - tome II. Trad. Louise Servicen. Mônaco: Éditions du Rocher, 1957b.

NIETZSCHE, Friedrich. Fragments posthumes: printemps - automne 1884. Trad. Jean Launay. Paris: Gallimard, 1982.

NIETZSCHE, Friedrich. Ecce Homo: como se chega a ser o que se é. Trad. José Marinho. 6. ㄹ ed. Lisboa: Guimarães Editores, 1997a.

NIETZSCHE, Friedrich. A genealogia da moral. 7. ed ed. Trad. Carlos José de Meneses. Lisboa: Guimarães, 1997b.

NIETZSCHE, Friedrich. O nascimento da tragédia / Acerca da verdade e da mentira. Trad. Teresa R. Cadete e Helga Hoock Quadrado. Lisboa: Relógio D’Água, 1997c.

NIETZSCHE, Friedrich. A gaia ciência. 6. ed. Trad. Alfredo Margarido. Lisboa: Guimarães Editores, 2000.

NIETZSCHE, Friedrich. Assim falava Zaratustra. 16. a ed. Trad. Alfredo Margarido. Lisboa: Guimarães, 2015.

NIETZSCHE, Friedrich. O crepúsculo dos ídolos. Trad. Artur Morão. Lisboa: Edições 70, 2018.

NIETZSCHE, Friedrich; RÉE, Paul; SALOMÉ, Lou von. Correspondance. Org. Ernst Pfeiffer. Trad. Ole Hansen-Love e Jean Lacoste. Paris: Presses Universitaires de France, 1979.

PASCOAES, Teixeira de. O Pobre Tolo. Porto: Renascença Portuguesa, 1924. 
PASCOAES, Teixeira de. Obras Completas de Teixeira de Pascoaes: V Volume - Cantos Indecisos / Londres / Dom Carlos / Cânticos / O Pobre Tolo. Amadora: Bertrand, 1970.

PASCOAES, Teixeira de. Obras Completas de Teixeira de Pascoaes: VIII Volume (Prosa II) - O bailado. Amadora: Bertrand, 1973.

PASCOAES, Teixeira de. Uma fábula (o advogado e o poeta). Porto: Brasília Editora, 1978.

PASCOAES, Teixeira de. As sombras / À ventura / Jesus e Pã. Lisboa: Assírio \& Alvim, 1996.

PASCOAES, Teixeira de. Desenhos. Posfácio de Bernardo Pinto de Almeida. Lisboa: Assírio \& Alvim, 2002.

PASCOAES, Teixeira de. Anjos e fantasmas (textos e imagens). Org. António Mega Ferreira. Lisboa: Assírio \& Alvim, 2003.

Recebido em 01 de novembro de 2020

Aprovado em 16 de setembro de 2021

Rodrigo Michell Araújo

Doutor em Filosofia pela Faculdade de Letras da Universidade do Porto, Portugal (2020). Investigador Colaborador do grupo "Raízes e Horizontes da Filosofia e da Cultura em Portugal", ligado ao Instituto de Filosofia da Universidade do Porto, e membro do CIMEEP, Centro Internacional e Multidisciplinar de Estudos Épicos (GT Épica, Filosofia e Religião), ligado à Universidade Federal de Sergipe.

Contato: rodrigo.literatura@gmail.com

(D) : https://orcid.org/0000-0002-0473-3995

A Revista Desassossego utiliza a Licença Creative Commons Attribution que permite o compartilhamento do trabalho com reconhecimento da autoria e publicação inicial neste veículo - Attribution-NonCommercial-NoDerivates 4.0 International (CC BY-NC-ND 4.0) e reconhece que os Autores têm autorização prévia para assumirem contratos adicionais separadamente para distribuição não-exclusiva de versão dos seus trabalhos publicados, desde que fique explicitado o reconhecimento de sua autoria e a publicação inicial nesta revista. 